\title{
Construction Enterprises Participating in PPP Project in Chinese Situation Research on the Incentive of Two Targets and One Target
}

\author{
Qian Zhang ${ }^{1}$, Yilin Yin ${ }^{1,2}$ \\ ${ }^{1}$ Tianjin University of Technology, Tianjin 300384 \\ ${ }^{2}$ Department of Management and Economics, Tianjin University, Tianjin 300072 \\ a18369387262@163.com, byinyilin575@163.com
}

Keywords: PPP project; two targets and one target; construction enterprise; incentive

\begin{abstract}
With the rise of the government and social capital cooperation (PPP) model in the Chinese market and its gradual expansion, construction enterprise in China's context have actively participated in PPP projects, but they have omitted the bid for secondary construction and generally implemented "two marks and one standard". Through the analysis of incentives for PPP projects, it shows that incentives are effective measures to increase the enthusiasm of social capital participation, improve agency efficiency, and promote social capital to actively achieve goals; this paper further summarizes the incentive measures for social capital through case studies, based on the greatest interests of construction enterprises. The goal is to obtain construction profits, identify the most critical incentive factors as "two targets and one target", and finally establishes an incentive effect model and the incentive mechanism to study the "two targets and one target" to entrust construction and operation to the same construction, and then affirms its active role.
\end{abstract}

\section{Introduction}

The policy document "Notice on Deepening the Cooperation between the Government and Social Capital in the Public Service Sector" (Cai Qian (2016) No. 90) clearly states: "For PPP projects involving engineering construction, equipment procurement or service outsourcing, If a social capital partner has been selected in accordance with the Government Procurement Law, and the partner is able to construct, produce or provide services on its own in accordance with the law, in accordance with the provisions of Article 9 of the "Regulations on the Implementation of the Tendering and Bidding Law," the partner may no longer perform the bidding." The stipulated behavior of such merger bidding is referred to by the industry as "two marks and one mark." The related literature [1-2] also uses the term "two signs and one sign" and the above meanings.

Referring to the current policy document, this article defines "two targets and one target" as the social capital selected by government procurement bidding method according to relevant laws and regulations to "build, produce, or provide services on its own" and can no longer carry out secondary construction. Tender. The object of this study is the construction enterprise, so it only refers to the behavior of no longer performing the second bidding for construction.

As China's PPP reform is actively promoted, the PPP market is rapidly expanding, and after construction companies become the social capital of PPP projects, the "two targets and one target" are generally used, which has a positive effect on the participation of construction companies in the project. However, through CNKI search, few scholars currently pay attention to the "two signs and one sign" common behavior that encourages construction companies to participate in the project. Therefore, this article mainly found that "two signs and one sign" involved construction companies in PPP. The intrinsic incentive mechanism of the project affirms its active role. 


\section{PPP Project Research Status}

\subsection{Status quo of construction enterprises participating in PPP projects}

A search of the keywords of "PPP Construction Enterprises" through CNKI found that there are not many related documents and the research is relatively simple.

Based on the research, it can be found that Dai Guohua, Zhou Yunkun, and Zheng Zechuan analyzed the risks faced by construction companies participating in PPP projects based on the perspective of risk management and control, and elaborated the types of risk control and methods of risk control. Wang Shuhai and Xu Anbang analyzed and summarized the financing modes and financing difficulties that can be used in PPP projects based on the perspective of project financing, and proposed the ideas and methods for expanding financing.

Since the PPP model was established in China in 2014, many projects have just entered the implementation stage. Therefore, the problems of PPP construction companies are basically concentrated on the opportunities and challenges that PPP brings to the construction companies and the management and control measures put forward when facing risks. It provides a solution path for construction companies to participate in the financing of PPP projects. At present, few scholars are concerned about the incentives of construction companies.

\subsection{Research on "Two Targets and One Target" in PPP Projects}

Xie Yupeng believes that Finance (2016) No. 90 (Expanded) explains the laws and regulations, and it is invalid; moreover, he thinks that when the PPP project needs to be re-tendered, the arguments are more relevant. The issue of competitive consultations.

Wang Jinmin thinks that if the two bids are not used together, the PPP project will be subject to secondary tendering for construction, and the right to contract for construction of social capital will be frustrated, which may cause delays and stagnation of the construction of the project, invalid construction contract, difficulty in settlement of the price, and Forced to revise the PPP contract price and other serious consequences.

Through the above-mentioned literature discovery, the research on the two targets and one target is still focused on its legal disputes, but it can be found through statistical data that whether it is the use of competitive negotiation procurement or the formation of a consortium bid with qualified contractors in actual operations, Still set up a project company, as long as there are construction companies to participate in and win the bid, most of them will no longer carry out secondary construction bidding. The relevant laws on this issue are in conflict with each other, the regulations are not clear, the controversy is constant, and the government departments only start to rectify the behavior of using two targets and one target under non-bidding. Therefore, this article does not discuss the legal issues of two targets and one target. Only from the perspective of economics, we study the mechanism of internal incentives for the two commonly-appeared bids.

\section{Incentive Research on PPP Projects}

\subsection{Incentive measures to attract social capital to participate in PPP projects}

The eighth quarterly report released by the National PPP Integrated Information Platform Project Library shows that there are a total of about 6,778 projects in the project library so far, and the proportion of the landing projects (at the stage of implementation and handover) is about 35.2\%. According to the above discussion, incentives are effective measures that enable social capital to actively participate in PPP projects, promote the realization of social capital interaction goals, and improve the quality and efficiency of project operations.

In order to attract social capital to actively participate in PPP projects, local governments have responded to the national call and introduced various incentive measures. By sorting out the literature on government incentive measures for PPP projects, a total of 15 social capital incentives for 
participating in PPP projects were extracted, as shown in Table.

Table 1 Government incentives for social capital to participate in PPP projects

\begin{tabular}{|c|c|c|c|}
\hline No. & $\begin{array}{c}\text { PPP project } \\
\text { stage }\end{array}$ & Incentive measures & Literature sources \\
\hline 1 & \multirow{2}{*}{$\begin{array}{c}\text { Project } \\
\text { identification }\end{array}$} & Complete PPP related policies & Zhao Fujun, Ou Chunzhi $\square$ \\
\hline 2 & & Clear, simplified approval process & Ye Xiaosu, Zhao Wei \\
\hline 3 & \multirow{6}{*}{$\begin{array}{c}\text { Project } \\
\text { preparation }\end{array}$} & Government commitment & Wang Yinglin \\
\hline 4 & & Clear cooperation & Ren Xiaocong, Ye Xiaosu, Zhou Haojia \\
\hline 5 & & Set a reasonable rate of return & Wu Yaping \\
\hline 6 & & Reasonable risk sharing & Ke Yongjian, Li Kaifeng \\
\hline 7 & & $\begin{array}{c}\text { Reasonable income distribution } \\
\text { mechanism }\end{array}$ & Ma Qiang \\
\hline 8 & & Tax relief benefits & Ke Yongjian, Wang Shouqing \\
\hline 9 & \multirow{3}{*}{$\begin{array}{c}\text { Project } \\
\text { procurement }\end{array}$} & Standardized bidding system & Liao Rui $\square$ \\
\hline 10 & & Selection of purchasing methods & Li Lihong \\
\hline 11 & & Two signs and one sign & Zhou Lanping \\
\hline 12 & \multirow{2}{*}{$\begin{array}{c}\text { Project } \\
\text { implementation }\end{array}$} & Government Investment Sponsorship & Ke Yongjian, Wang Shouqing \\
\hline 13 & & Operational performance assessment & Yuan Jingfeng, Ren Zhitao \\
\hline 14 & \multirow{2}{*}{ Project handover } & Exit mechanism & Wang Shancai \\
\hline 15 & & Transfer method & Wang Wei \\
\hline
\end{tabular}

At present, PPP projects generally adopt market testing methods before procurement, and explore whether social capital is most attractive to PPP projects or whether the design of verification project plans is attractive. The above measures are all tested through questionnaires or actual PPP projects, and are considered to increase the enthusiasm of the social capital to participate in the PPP project.

\subsection{Key incentives for construction enterprises based on interest objectives}

The PPP model has brought great changes to the construction industry and construction companies. Under the PPP model, the most important purpose of the construction companies participating in the PPP project is to obtain construction contracting rights so as to maximize their own interests and thus promote the sustainable development of the main business.

Therefore, although Table 1 is an effective measure to motivate social capital to actively participate in PPP projects, for construction companies, the incentive measures that can guarantee their acquisition of construction rights are the most crucial. From this, it can be seen that the most direct realization is that This goal is "two targets and one target", and at the same time, it can realize the integration of investment and construction management. As long as the construction company participates in the PPP project and successfully wins the bid for social capital, the "two targets and one target" can ensure that the construction company and the project company directly sign the construction general contract, and there is no need for secondary construction bidding. Otherwise, after the purchase of PPP social capital, a second bidding for construction will be carried out, and the right to contract for construction of social capital may be lost. This not only increases the cost and time for procurement, but also poses risks for construction companies to participate in PPP projects and reduces their participation. Enthusiasm.

\section{Design of "Two Targets and One Target" Incentive Effect Model}

\subsection{Basic assumptions of the incentive effect model}

Iossaand Martimort et al. give definitions of positive and negative externalities in the PPP model. Their research shows that positive externalities refer to the efforts of social capital to improve quality in the construction phase, which is conducive to lowering operating costs; negative externality means that providing high-quality efforts can not reduce the cost of the operation phase. Or when the private 
sector optimizes the design of PPP projects, it also needs to acquire new skills for the management of PPP projects and increase the operating costs. When tasks are entrusted to the same social capital in the construction phase and operation phase, the incentives to improve infrastructure quality and the prevention of poor quality regulations can be used to reduce the moral hazard that builders do not exert their best efforts to internalize the external to improve the quality of infrastructure. Sex. If the PPP project is not a high-quality PPP project during the construction phase, it will increase the operating costs. In particular, when the PPP project is not tied up in the construction and operation phase, it will bring negative externalities to its operation.

Assumption: $\delta$ represents externality, $\mathrm{G}$ represents government, B represents construction contractor, O represents operator, and BO represents two companies and one contractor and operator.

Hypothesis 1: The best effort of agents to improve the construction quality of PPP projects is recorded as $e_{1}$, he agent's effort to reduce operating costs is marked as $e_{2}$. In order to simplify the process, $\varphi\left(e_{1}\right)=\frac{e_{1}^{2}}{2}, \varphi\left(e_{2}\right)=\frac{e_{2}^{2}}{2}$, a change in the exertion level is not sufficient to influence the marginal opportunity cost change of another best effort level. In other words, there is no scope economy between the two efforts.

Hypothesis 2: The improvement of the quality of PPP projects and the reduction of operating costs will directly reflect the bundled benefits. Assume that the social benefits associated with an agent's best efforts must consider two factors: one is the consumer's demand $\mathrm{D}$, and the other is the formation and operation of public goods. Assume that the price corresponding to the consumer's inelastic demand for service is $p_{0}$ (ie usage fee).

$$
D(p)=\left\{\begin{array}{c}
d_{0}+d e_{1}+\mu, p \leq p_{0} \\
0, p>p_{0}
\end{array}\right.
$$

Among them, d0 is the basic demand, improving the quality of e1, the demand will increase; rent is $\mathrm{d}, \mathrm{d}>0$, quality and demand are proportional to each other, because $e_{2}$ is to reduce the operating cost of the best effort, do not consider this best effort The role of demand; Demand risk $\mu \sim \mathrm{N}\left(0, \sigma_{\mu}^{2}\right)$ 。 Consider the risk of bundling and demand, assuming that the government can obtain all the benefits that are obtained in consideration of the risk of bundling and demand, and the social benefits at this time $\mathrm{SB}=b_{0}++p_{0}\left(d_{0}+d e_{1}\right)+b_{1} e_{1}+\mu+b_{2} e_{2}$, The social benefits obtained above cannot be confirmed, where $b_{0}$ represents the basic income level of the service and has nothing to do with the extent of the best effort. $b_{1}, b_{2}$ represent the marginal benefits of the agent's efforts. $\left(b_{1}>0, b_{2}>0\right)$ 。

Social capital service costs $C\left(e_{1}, e_{2}\right)=C_{0}-e_{2}-\delta e_{1}+\varepsilon^{[13]}$, C Access to operational risk when social capital manages assets can be written into contracts 。Among them, $C_{0}$ is the sunk cost of the service, and $\varepsilon$ is a random variable that obeys $\mathrm{N}(0, \sigma 2)$. It should be emphasized that $\delta$ represents externalities, and $\delta<0$ means that the construction of high-quality PPP projects will increase the operating costs, that is negative externalities; $\delta>0$ means that the construction of high-quality PPP projects will reduce operating costs, that is, positive externalities.

Hypothesis 3: $G$ with the goal of maximizing social welfare is risk-neutral. The agent aims at maximizing his own expected utility for the purpose of avoiding risks. What needs to be emphasized is that assuming that social capital is a utility function, social capital has a constant absolute risk of evasion in this function, and the risk aversion coefficient is $r(r>0)$.

\subsection{Basic reference for incentive effect model}

Benchmarking should be considered before creating split and tie models. Assuming that the efforts of construction contractor $\mathrm{B}$ and operator $\mathrm{O}$ can confirm observable and loadable contracts, $\mathrm{G}$ can use the contractual mandatory guarantee to implement the best efforts. A benchmark model is thus obtained, which is in a state of complete information, that is, an optimized contract design where symmetry information is observable at the best effort level.

When the best effort is achieved to achieve optimality, the contract will force companies to choose the optimal solution to achieve the goal of maximizing social welfare (social welfare is represented 
by $\mathrm{W}(\cdot))$.

$$
\begin{gathered}
W=E(S B)-\varphi\left(e_{1}\right)-E(C)-\varphi\left(e_{2}\right) \\
=b_{0}+b_{1} e_{1}+b_{2} e_{2}+p_{0}\left(d_{0}+d e_{1}\right)-\left(C_{0}-e_{2}-\delta e_{1}\right)-\frac{e_{1}^{2}}{2}-\frac{e_{2}^{2}}{2}
\end{gathered}
$$

Maximized:

$$
\left(e_{1}^{F B}, e_{2}^{F B}\right)=\left(b_{1}+\delta+p_{0} d_{0}, b_{2}+1\right)
$$

Further:

$$
W^{F B}=b_{0}+\frac{\left(b_{1}+\delta+p_{0} d\right)^{2}}{2}-C_{0}+\frac{\left(1+b_{2}\right)^{2}}{2}+p_{0} d_{0}
$$

The preconditions for obtaining the optimal level of best effort are: consider the marginal social value and marginal cost of the best effort; the precondition for obtaining the best effort to reduce the operating cost is: consider the marginal benefit of reducing the operating cost and the marginal impact of the effort on the profit $b_{2}$. With the marginal inefficiencies $\left(e_{2}\right)$ of money, in other words, the precondition for the government to obtain the optimal level of effort $\left(e_{1}^{F B}, e_{2}^{F B}\right)$ is that the marginal benefits and marginal costs of best effort are equal.

\section{Analysis of Incentive Effect Model of "Two Targets and One Target"}

In the traditional government procurement model, after the completion of a given construction contractor $\mathrm{B}$, the government $\mathrm{G}$ first purchases the PPP project from $\mathrm{B}$, and then selects the operator O. Therefore, under the circumstance that the level of effort cannot be confirmed, it is necessary to study whether to use the two labels and one label to entrust the construction and operation of the bundle to the same company, that is, to use the "two labels and one label" to entrust the construction and operation to the same contracting party. The BO implementation; or non-"two standard and one standard", construction and operation by the different construction contractor B and operator O responsible.

Research hypothesis: government, construction contractor, operator's payment is related to cost

$$
\begin{aligned}
& t_{0}(C)=m-n C \\
& t_{\mathrm{B}}(c)=\alpha-\beta C
\end{aligned}
$$

In the formula, $\mathrm{nC}, \beta \mathrm{C}$ are incentive rewards, $\mathrm{m}, \alpha$ represent the fixed payment amount, and $\mathrm{n}, \beta$ are the incentive intensity factors of the best effort level.

$$
\text { type of contract }=\left\{\begin{array}{l}
0, \text { Cost Plus Contract } \\
1, \text { Fixed price contract }
\end{array}\right.
$$

\subsection{Incentives in the case of construction and operation of splitting}

According to the operator's linear contract return principle $t_{0}(C)$, the operator's expected utility is maximized (function $U(\cdot)$ indicates the utility of the enterprise), and in this case, the incentive constraint is

$$
U_{\mu}^{o}=m-\frac{r \sigma^{2} n^{2}}{2}-\frac{e_{2}^{2}}{2}-n\left(C_{0}-e_{2}-\delta e_{1}\right)
$$

In the formula, $\frac{r \sigma^{2} n^{2}}{2}$ In order to motivate operators to work hard for risk compensation.

Maximized:

$$
\frac{\partial U_{u}^{0}}{\partial e_{2}}=n-e_{2}=0
$$




$$
e_{2}=n
$$

Under the operator's best efforts, the contractor's expected utility is maximized, and the incentive constraint is

$$
U_{\mu}^{B}=\alpha-\beta\left(C_{0}-e_{2}-\delta e_{1}\right)-\frac{e_{1}^{2}}{2}-\frac{r \sigma^{2} \beta^{2}}{2}
$$

In the formula: $\frac{r \sigma^{2} \beta^{2}}{2}$ In order to motivate construction contractors to do their best to risk return. Maximized:

$$
\frac{\partial U_{u}^{0}}{\partial e_{12}}=\beta \delta-e_{1}=0 \text {, 即 } e_{1} \geq 0
$$

Then:

$$
e_{1}=\left\{\begin{array}{c}
\beta \delta, \delta>0 \\
0, \delta \leq 0
\end{array}\right.
$$

If the government obtains the price advantage of full bargaining before then, all rents are extracted. Taking into account incentive constraints (1) and (2), the government maximizes social welfare as follows:

$$
\begin{aligned}
W_{u} & =b_{0}+b_{1} e_{1}+b_{2} e_{2}+p_{0}\left(d_{0}+d e_{1}\right)-\left(C_{0}-e_{2}-\delta e_{1}\right)-\frac{e_{1}^{2}}{2}-\frac{e_{2}^{2}}{2}-\frac{r \sigma^{2} n^{2}}{2}-\frac{r \sigma^{2} \beta^{2}}{2} \\
& =b_{0}-C_{0}+p_{0} d_{0}+\left(b_{1}+\delta+p_{0} d\right) e_{1}+\left(b_{2}+1\right) e_{2}-\frac{e_{1}^{2}}{2}-\frac{e_{2}^{2}}{2}-\frac{r \sigma^{2} n^{2}}{2}-\frac{r \sigma^{2} \beta^{2}}{2}
\end{aligned}
$$

Get:

$$
e_{2 u}=\frac{1+b_{2}}{1+r \sigma^{2}} ; e_{1 u}=\left\{\begin{array}{c}
\frac{b_{1}+\delta+p_{0} d}{1+\frac{r \sigma^{2}}{\delta^{2}}}, \delta>0 \\
0, \delta \leq 0
\end{array}\right.
$$

So get:

When $\delta>0$ :

$$
W_{u}=b_{0}-C_{0}+p_{0} d_{0}+\frac{\left(1+b_{2}\right)^{2}}{2\left(1+r \sigma^{2}\right)}+\frac{\left(b_{1}+\delta+p_{0} d\right)^{2}}{2\left(1+\frac{r \sigma^{2}}{\delta^{2}}\right)}
$$

(2) $\delta \leq 0$

$$
W_{u}=b_{0}-C_{0}+p_{0} d_{0}+\frac{\left(1+b_{2}\right)^{2}}{2\left(1+r \sigma^{2}\right)}
$$

\subsection{Incentives under construction and operational bundles}

In the case of two bids and one bid, government $\mathrm{G}$ entrusts the PPP project to a company $\mathrm{BO}$ and constructs and operates two phases of work. Then the BO will jointly choose the optimal level of best effort and ultimately maximize the expected payment. which is

$$
\max _{\left(e_{1}, e_{2}\right)} \alpha-\beta\left(C_{0}-\tilde{e}_{2}-\delta \tilde{e}_{1}\right)+m-n\left(C_{0}-\tilde{e}_{2}-\delta \tilde{e}_{1}\right)-\frac{\tilde{e}_{1}^{2}}{2}-\frac{\tilde{e}_{2}^{2}}{2}-\frac{r \sigma^{2} n^{2}}{2}-\frac{r \sigma^{2} \beta^{2}}{2}
$$

Get:

$$
\begin{aligned}
& e_{2}=\beta+n \\
& e_{1=}\left\{\begin{array}{c}
(\beta+n) \delta, \delta>0 \\
0, \delta \leq 0
\end{array}\right.
\end{aligned}
$$


When $\delta \leq 0, e_{1}=0$, G maximizes social welfare

$$
\max W_{b}=b_{0}+b_{2} e_{2}+p_{0} d_{0}-\left(C_{O}-e_{2}\right)-\frac{e_{1}^{2}}{2}-\frac{r \sigma^{2} n^{2}}{2}
$$

Get:

$$
e_{2 b}=\frac{1+b_{2}}{1+\frac{r \sigma^{2}}{2}}, e_{1 b}=0
$$

Therefore,

$$
W_{b}=b_{0}-C_{0}+p_{0} d_{0}+\frac{\left(1+b_{2}\right)^{2}}{2\left(1+\frac{r \sigma^{2}}{2}\right)}
$$

When $\delta>0, e_{1}=(\beta+n) \delta$, G maximizes social welfare

$$
\begin{array}{r}
\max W_{b}=b_{0}+b_{1} e_{1}+b_{2} e_{2}+p_{0}\left(d_{0}+d e_{1}\right)-\left(C_{0}-e_{2}-\delta e_{1}\right)-\frac{e_{1}^{2}}{2}-\frac{e_{2}^{2}}{2}-\frac{r \sigma^{2} n^{2}}{2}-\frac{r \sigma^{2} \beta^{2}}{2} \\
\text { Get: } 1+b_{2}+\left(b_{1}+\delta+p_{0} d\right) \delta+r \sigma^{2} n^{2}=\left(1+r \sigma^{2}+\delta^{2}\right) e_{2} \\
n=\frac{e_{2}}{2}
\end{array}
$$

Thereby:

$$
\begin{array}{r}
e_{2 b}=\frac{1+b_{2}+\left(b_{1}+\delta+p_{0} d\right) \delta}{1+\frac{r \sigma^{2}}{2}+\delta^{2}} \\
e_{1 b}=e_{2} \delta
\end{array}
$$

Therefore,

$$
W_{b}=b_{0}-C_{0}+p_{0} d_{0}+\frac{\left(1+b_{2}+\left(b_{1}+\delta+p_{0} d\right) \delta\right)^{2}}{2\left(1+\frac{r \sigma^{2}}{2}+\delta^{2}\right)}
$$

\subsection{Conclusion of construction and operation bundling effect}

From the above analysis, we can see that when there is negative externality, that is, $\delta \leq 0, e_{1}=0$, due to efforts to improve quality will increase operating costs, can not get direct remuneration. Therefore, construction contractors and operators will not actively strive to improve quality. When $\delta>0$, construction contractors and operators are making efforts to improve the quality of infrastructure construction. This part of the effort will be internalized to reduce operating costs. In this case, choosing a fixed price contract will incentivize the improvement of infrastructure quality.

\section{Conclusion}

According to the provisions in Article 9(3) of the Implementing Regulations of the Tendering and Bidding Law, the government and social capital cooperation (PPP) project can see that if the procurement construction enterprise is a social capital, it may no longer carry out the secondary construction bidding, that is, "Two signs and one sign" phenomenon is widespread in today's PPP project procurement. The purpose of the construction company is to maximize its own interests by obtaining construction control rights, and the "two standards and one standard" as a key incentive to ensure that construction companies participate in the acquisition of construction rights and interest objectives of PPP projects. This paper further proves that through the establishment of an incentive effect model, "Two Standards and One Standard” entrust construction and operational bundling to the 
same construction company. Under positive externalities, it has the effect of making construction companies strive to improve construction quality and reduce operating costs. Furthermore, it is affirmed that the "two targets and one target" have an important incentive effect for improving the enthusiasm of construction enterprises to participate in PPP projects.

\section{References}

[1] Sun Xinyan, Yin Yulin, Wang Xiang. Research on the Process Reengineering of Life Cycle Consultation of PPP Projects by Engineering Cost Consultation Enterprises [J]. Project Management Technology, 2017, 15(6): 41-47.

[2] Wang Yilin. Research on the Application of PPP Mode in Taihangshan Highway Project in Hebei[D]. Chengdu: Southwest Jiaotong University, 2017.

[3] Dai Guohua. Consideration of Construction Enterprise Group Participating in PPP Project Risk Management[J]. Finance and Accounting,2016(12):8-12.

[4] Zhou Yunkun. Research on risk control of A construction company in PPP mode[D]. Kunming: Yunnan University, 2016.

[5] Zheng Zechuan, Zong He. Opportunities and Risks of PPP to Construction Enterprises[J]. Architecture, 2015(15):8-13.

[6] Wang Shuhai. Financing Issues and Solutions for Construction Enterprises Participating in PPP Projects[J]. Construction and Design for Engineering,2015(12):11-12.

[7] Xu Anbang. Research on the financing of small and medium-sized construction companies[D]. Wuhan: Central China Normal University, 2012.

[8] Xie Yupeng. Special legislation on PPP should be put on the agenda [N]. Shanghai Securities News, 2016-10-20(008).

[9] Wang Jinmin. Second Bidding Risk of PPP Project Construction and Prevention and Control[J]. Construction Enterprise Management,2016(5):111-112.

[10] Liu Liyun. Research on Risk Governance of PPP Project Investment: Based on Incentive and Third Party Supervision[D]. Hefei: University of Science and Technology of China, 2010.

[11] IOSSA E, MARTIMORT D. Corruption in public-private partnerships, Incentives and contract incompleteness[J]. Cesifo Dice Report,2014, 12(3):14-16.

[12] MARTIMORT D, POUYET J. To build or not to build: normative and positive theories of public-private partnerships[J]. International Journal of Industrial Organization,2008,26(2):393-411.

[13] Yao Dongxi, Li Junlin. Efficiency difference under conditional satisfaction: Comparison between PPP model and traditional model[J]. Reform,2015(2):34-42. 